Portland State University

PDXScholar

$11-13-1981$

\title{
A Comparison of Two Articulation Carry-Over Techniques
}

Robyn Schwartz

Portland State University

Follow this and additional works at: https://pdxscholar.library.pdx.edu/open_access_etds

Part of the Speech and Hearing Science Commons, and the Speech Pathology and Audiology Commons

Let us know how access to this document benefits you.

\section{Recommended Citation}

Schwartz, Robyn, "A Comparison of Two Articulation Carry-Over Techniques" (1981). Dissertations and Theses. Paper 3221.

https://doi.org/10.15760/etd.3212

This Thesis is brought to you for free and open access. It has been accepted for inclusion in Dissertations and Theses by an authorized administrator of PDXScholar. Please contact us if we can make this document more accessible: pdxscholar@pdx.edu. 
AN ABSTRACT OF THE THESIS OF ROBYN SCHWARTZ for the Master of Science in Speech Communication, presented November 13, 1981.

Title: A Comparison of Two Articulation Carry-over Techniques.

APPROVED BY MEMBERS OF THE THESIS COMMITTEE:

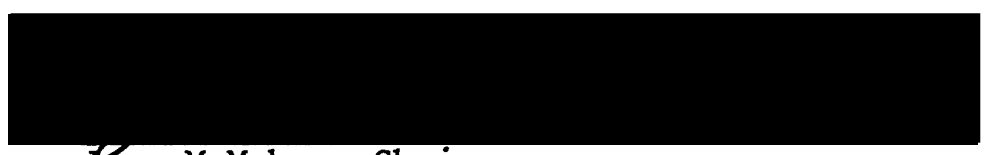

Joan McMahon, Chairman
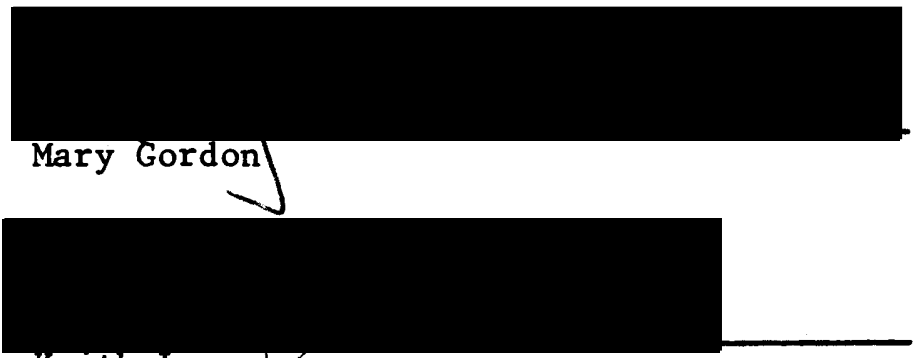

Keith Larsor

The purpose of this investigation was to determine the comparative effectiveness of two articulation carry-over techniques. It was hoped that through this comparison answers regarding carry-over results could be ascertained for purposes of aiding public school clinicians currently spending the majority of management time on carry-over. If one technique was found to be superior, its use among speech pathologists might aid in changing this time allocation trend.

Identical management programs using the Collins and Cunningham (1977) /S/AMP three times weekly were employed by two random groups involving two participants each. All subjects displayed a lingually distorted $/ \mathrm{s} /$ and $/ z /$. Upon achievement of $/ \mathrm{s} / / \mathrm{z} /$ production in 
conversation in the clinic setting two subjects were assigned carryover tasks using a self-monitoring procedure. The remaining two subjects were assigned carry-over tasks using significant others. All subjects utilized grid cards as the recording device and both groups continued to meet with the investigator throughout carry-over for charting purposes only.

The results indicated the self-monitoring technique to be more effective. The self-monitors demonstrated greater gain of correct production in all contexts studied. However, these results must be viewed guardedly due to possible skewing factors of age, maturity, attendance, reading ability, movement criteria, motivation, and honesty of reporting. 
A COMPARISON OF TWO ARTICULATION

CARRY-OVER TECHNIQUES

$$
\text { by }
$$

ROBYN SCHWARTZ A thesis submitted in partial fulfillment of the
requirements for the degree of

\author{
MASTER OF SCIENCE \\ in \\ SPEECH COMMUNICATION
}

Portland State University

1982 
TO THE OFFICE OF GRADUATE STUDIES AND RESEARCH:

The members of the Committee approve the thesis of Robyn

Schwartz presented November 13, 1981.

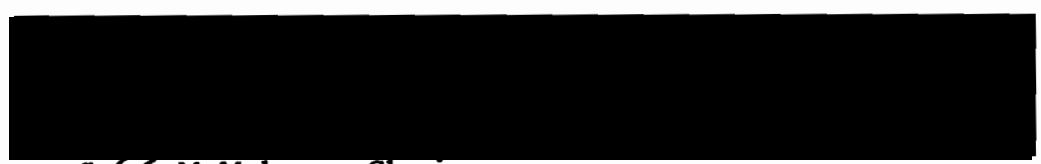

Jorn McMahon, Chairman
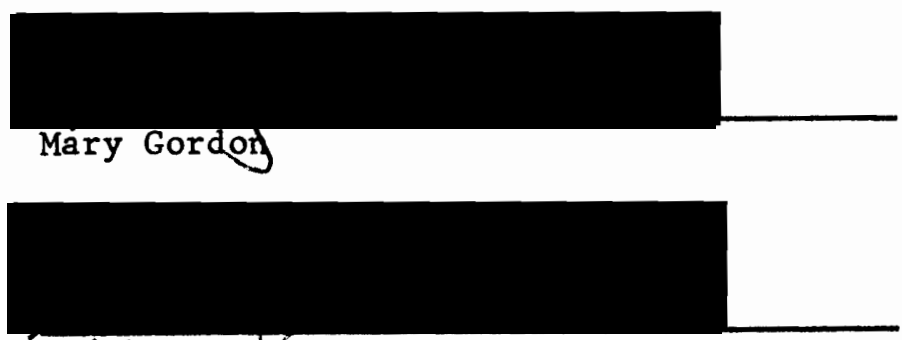

Keith Larson

APPROVED :

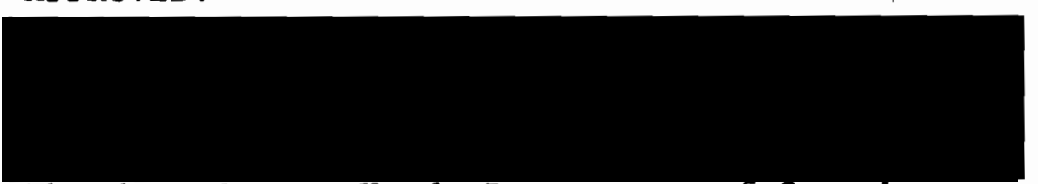

Theodore Grove, Head, Department of Speech

Communication

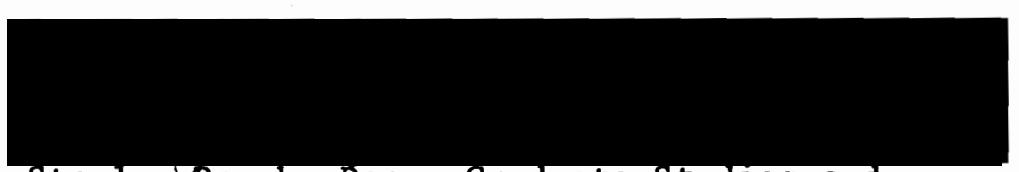

stanley Rauch, Dean, Graduate studies and

Research 
TABLE OF CONTENTS

Page

LIST OF TABLES ..................... . . v

LIST OF FIGURES ................... . . . vi

CHAPTER

I INTRODUCTION . . . . . . . . . . . 1

Statement of Purpose ........... 3

Operational Definitions.......... 4

II REVIEW OF THE LITERATURE . . . . . . . . . . 5

Introduction ............. 5

Intra-clinical Methods .......... 6

Extra-clinical Methods ........... 9

III METHODS AND PROCEDURES . . . . . . . . . . . 16

Methods................ 16

Subjects

Diagnostic Instrumentation

Program Instrumentation

Procedures .............. . 18

Test Administration

Program Administration

Post-test Evaluation

Data Analysis

IV RESULTS AND DISCUSSION . . . . . . . . . . 21

Results.............. 21

Discussion . . . . . . . . . . 25

Management Influences on Carry-over ...... 25 
CHAPTER

Page

Influences on Carry-over . . . . . . . . . .

Motivation

Age and Maturity

Attendance

Management Procedures

Criterion for Carry-over

Uncontrolled Variables

Effect of Factors on Results . . . . . . . . 30

V SUMMARY AND IMPLICATIONS . . . . . . . . . . . . 32

Summary . . . . . . . . . . . . . . 32

Implications . . . . . . . . . . . . . 33

Research

Clinical

BIBLIOGRAPHY . . . . . . . . . . . . 36

APPENDICES ........................... 40 


\section{LIST OF TABLES}

TABLE

Page

I Average percentage of correct conversational productions during two covert observations

II McDonald Deep Test single words pre- and post-test results... . . . . . . . . . . .

II Conversational sample pre- and post-test results percentage correct . . . . . . . . . .

IV Correct productions reported in carry-over compared to attendance . . . . . . . . . . . . . . 


\section{LIST OF FIGURES}

1 Correct responses recorded on grid cards during carry-over . . . . . . . . . . . . . . . 24 
CHAPTER I

\section{INTRODUCTION}

Articulation is a learned set of motor events (Bankson and Byrne, 1972). Verbal communication necessitates a proficiency of articulation for adequate understanding between speaker and listener. Disorders of articulation compromise this commicative understanding and may effect a social stigma toward the speaker. The proficiency necessary to produce speech sounds correctly is functionally inadequate in approximately 76 percent of the public school population exhibiting speech deviancies (Worthley, 1970; Van Riper, 1972). This incidence results in speech-language pathologists devoting a majority of time to children displaying functional articulation disorders (Chapman, Herbert, Avery, and Selmar, 1961; Van Riper, 1972). Thus, speech-language pathologists are well acquainted with the identification and remediation of these disorders.

Traditionally remediation of functional articulation disorders has involved the modification of speech sound production through five skill acquisition steps, followed by mastery of a sound carry-over stage (Wright, Shelton, and Arndt, 1969; Diedrich, 1971; Wing and Heimgartner, 1973). Achievement of carry-over seems to be related to proficiency of sound production during the previous acquisition stages (Wright et a1., 1969). Articulatory performance is monitored through a succession of steps and is well defined by the literature. These 
include: 1) auditory discrimination, 2) phoneme production in isolation or syllables, 3) phoneme production in words, 4) phoneme production in phrases and sentences, and 5) phoneme production in conversational speech (Chisum, Shelton, Arndt, and Elbert, 1969; Van Riper, 1972; Wing and Heimgartner, 1973; Chisum, 1974). Articulation management may utilize some or all of these steps to achieve correct intraclinical sound production. However, error-free articulation in the clinic usually does not result in the accomplishment of sound habituation, or carry-over (Wright et al., 1969).

Mowrer (1971) defines effective carry-over as the transfer of correct articulation in speaking situations outside the clinical setting. Conversational speech generally comprises these situations as the client gives only marginal attention to articulation and more attention to the content and action of the conversation (Powers, 1971; Winitz, 1975). The transfer of training in carry-over is achieved through a variety of means and devices less strictly defined than the acquisition stages. The terminal carry-over goal may involve automatization or habituation of the target sound, stimulus generalization to a variety of settings, the development of client responsibility, and intrinsic motivation (Chisum et al., 1969; Bankson and Byrne, 1972; Mowrer, 1977). Realization of these factors may facilitate phoneme carry-over.

The techniques utilized to achieve terminal carry-over are diverse, primarily non-standardized, and modified according to clinician and client needs. Since little is known about critical carryover variables, it is not surprising that speech-language pathologists 
devote the bulk of articulation management time to terminal carry-over procedures (Enge1, 1968; Coste11o and Bosler, 1976; Johnson, 1976). Polson's (1980) sample of Oregon speech pathologists reported spending approximately twice as much time on carry-over as skill acquisition. This information suggests an inefficiency of time, labor, and money used for carry-over attainment. Thus, it benefits speech pathologists and administrators alike to 1) review currently used carry-over techniques, 2) evaluate them in terms of efficiency (time, labor, and financial costs), and 3) determine which procedures are advantageous to use.

\section{Statement of Purpose}

The purpose of this investigation was to determine the comparative effectiveness of two articulation carry-over techniques. The first technique involved clients seeking out individuals in their environment and practicing the target sound with these persons. The second technique involved clients implementing a self-evaluation procedure for target sound practice. Answers to the following questions were sought:

1) Did both techniques achieve carry-over?

2) Did one technique facilitate conversational carry-over achievement within a shorter time period?

3) Was one technique more cost efficient in terms of clinician-child contact time, number of correct responses, and/or reinforcement schedules maintained? 
Operationa1 Definitions

\section{Carry-over}

The extension of a target speech behavior production from trained clinical situations to untrained environmental situations.

Discriminative stimulus

An antecedent stimulus in whose presence a specific response obtains a reinforcer.

Effective

The production of desired results as defined by the speechlanguage pathologist.

\section{Positive Reinforcement}
A consequent stimulus whose presentation following a response increases the strength and frequency of that response and increases the probability that the same response will occur again in the presence of the same or similar antecedent stimulus.

\section{Stimulus Generalization}

A response conditioned in the presence of the training stimulus will also occur in the presence of other similar stimuli without reinforcement. 
CHAPTER II

REVIEW OF THE LITERATURE

\section{Introduction}

Modification of phoneme misarticulation requires an awareness of correct production and a systematic change of habitual responses. Regardless of the technique used to achieve carry-over the procedures need to be sequentially presented from least to most difficult. Systematic sequential changes require behavioral engineering of the clinical environment to define expected responses and produce maximum results. Operant behavior modification procedures aid in manipulating environments to achieve satisfying results.

Learning necessitates certain antecedent and consequent events known as stimuli, responses, and reinforcers. Behavior modification paradigms entail appropriate management of these events, as a defined knowledge will aid the management process by limiting the possibilities of teacher and student behavior, thus ensuring situational control. Stimulus, defined simply, is any environmental object or event (Rach1in, 1976). A discriminative stimulus $\left(S^{D}\right)$ refers to one which is capable of eliciting a predicted response or observable, measurable activity. This capability results from a neutral stimulus being paired with a reinforcer, eventually establishing a relationship between the stimulus and the response (Sundel and Sundel, 1975). Stimulus control is the condition under which a response reliably 
occurs only in the presence of a discriminative stimulus and not in the presence of a neutral stimulus. Stimulus generalization refers to the tendency to perform a response in a new situation because of the situation's similarity to the one in which the response was learned. This tendency seems to be proportional to the degree of similarity. Stimulus generalization, one goal of carry-over, describes a transfer of training evident between every skill acquisition step in a program. Carry-over refers to the transfer of training from the total program to environmental situations in which direct training has not occurred. Another goal of carry-over is the development of durable reinforcers. Any favorable consequence of a response that increases the occurrence probability of that response describes a reinforcer. Durable reinforcers in conversational situations are generally social or intrinsic to the client. Reinforcers tend to initiate or maintain motivation toward a task and need to be considered when reviewing carry-over practices (Sundel and Sundel, 1975; Mowrer, 1977).

There are two general types of carry-over practices that encompass the array of available techniques. The first promotes articulation carry-over through selection of practice materials and through structuring the procedures of management. The second involves arranging for practice and reinforcement in extra-clinical situations by parents, peers, or teachers (Engel and Groth, 1976).

\section{Intra-clinical Methods}

Promoting carry-over through in-clinic practice materials has infinite possibilities dependent only on the innovation of a clinician. 
A sampling of alternatives will be presented here. Generally, in-clinic carry-over activities are aimed at increasing response automatization. Extension of stimulus generalization is, however, limited in the clinic due to $S^{D}$ constraints and a lack of situational approximation to daily life activities.

One method which attempts to bridge the situational approximation gap is integrating speech management with the school's language arts program (Sutton, 1955). The rationale for this first method encompasses four purposes: 1) to afford a transmission vehicle for speech correction principles, 2) to increase the mutual understanding of professional areas between clinician and teacher, 3) to provide the child opportunity to assume responsibility and initiative in the carry-over process, and 4) to establish judging criteria for suitability and effectiveness techniques and materials involved with the child (Sutton, 1955). Scaled objectives consistent with the language arts curricula are provided for each grade level. These goals are combined with speech acquisition objectives to achieve mastery. In this manner, materials may be readily available to the clinician, and the child's speech transition between clinic and classroom is facilitated.

A second method incorporating an extension of activities found in a regular classroom involves the utilization of creative dramatics to facilitate speech correction (McIntyre and McWilliams, 1959). This technique is a group venture encouraging students to freely express themselves through improvised drama. The authors suggest creative dramatics be used as an adjunct to regular speech management for pur- 
poses of expanding interpersonal development. Children may profit using this procedure by becoming more willing to use speech in everyday life (McIntyre and McWilliams, 1959).

A third more traditional approach to carry-over employs motivation generated by play activities. These activities are designed to be altered so the child is practicing speech drills (Mowrer, 1970). Many clinicians believe the play environment fosters informality, causing the child to emit a less deliberate response. Games afford a pleasurable vehicle through which intervention may be viewed by client and clinician. Black and Ludwig (1956) believe games are valuable tools for increasing efficiency and adding interest, motivation, and variety to the sessions. Although the authors support play activities, they warn that the primary objective of the lesson should be maintained. Thus, the game should be relevant and appropriate to the child's ability level, provide frequent speech opportunities, be integrated with classroom work when possible for educational advantage, and provide reinforcement only for discernible improvement of speech performances. Other authors agree with this standpoint (Engel, 1968 ; Mowrer, 1970).

With the advent of behavioral methodologies, a fourth method, commercial speech programs, became readily available. The structured program procedures vary widely but maintain certain behavioral premises. These include maximum response opportunities, maximum response correctness, and immediate reinforcement. Many commercial programs are standardized and possess specifically defined objectives. This provides clinicians greater accountability and ease of lesson planning. 
Carrier's (1977) program involves mother participation while Gerber's (1970) Goal Kit uses six steps to self-monitoring. Mowrer, Baker, and Schutz (1970) designed the S-Pack, a programmed articulation kit for modification of frontal lisps. The clinician's kit is devised to stimulate and practice the target sound. A parent kit attempts to extend and refine these correct responses in conversational speech settings. Ryan (1971) evaluated the S-Pack's effectiveness with third graders and found positive results. Evans and Potter (1974) studied the program's effectiveness when administered by sixth graders. The authors indicated that trained students can administer this program with good results.

Success with programmed articulation management is reported in the literature (Sloane and MacAulay, 1968; Harryman and Kresheck, 1971; McLean and Raymore, 1972). Gray (1974) compared programmed articulation on controlled laboratory circumstances and field situations and observed that equivalent results can be obtained. Worthley (1970) concluded that programmed speech intervention received significantly higher scores than non-programmed strategies with respect to articulation maintenance. Thus, it appears that programmed articulation management is a viable alternative for clinician use.

\section{Extra-clinical Methods}

Arranging extra-clinical activities that promote articulation carry-over can involve the participation of various people, such as teachers, aides, parents, coaches, or peers. The use of these significant people in the child's environment aids carry-over by increasing 
the discriminative stimuli in that environment.

Marquardt (1959) proposes the incorporation of "speech pals" for peer moral support to reinforce extra-clinical phoneme productions. Essentially, the clinician enlists the aid of a child with acceptable speech to help with the carry-over process. The speech pals should be cautiously chosen, exhibiting such characteristics as patience, helpfulness, and having a leader-type but non-threatening personality. The speech pal accompanies the client to "speech class," receiving listening training before being permitted to reinforce the client's productions outside of clinic. Marquardt's (1959) theoretical base assumes that children learn behavior more quickly from peers.

A variation of peer monitoring is exemplified by Engel and Mahoney (1971). Classroom friends were assigned to monitor each client's speech productions. The monitors were trained to mark an $X$ on paper for each correct /s/ heard. Over a two-week treatment period the peer monitor recording the most correct responses received a prize. A conclusion assumed by the authors indicated that rewarding persons in the child's environment when he talks better appears to reduce his rate of misarticulations. The rationale for this technique is based on the promotion of social reinforcement. Engel, Brandriet, Erickson, Gronhovd, and Gunderson (1966) suggest the clinician determine which admired persons in the client's environment could be utilized for carry-over activities. In this manner, the client exercises his novel articulation skills in the presence of a significant reinforcer under untrained circumstances. Thus, if response and reinforcement are executed accurately, the person utilized and the situ- 
ation possess the potential to become an $s^{D}$ for the client. Using a similar procedure, Kalash (1970) implemented a carryover technique represented by a classroom contingency program. Again, a peer tracked the number of correct productions emitted by the client. Upon achieving 500 correct productions, the entire class received a treat. The author concluded that peer influence used to promote articulation carry-over might be significant motivation for positive change. Johnston and Johnston (1972) reached similar conclusions. Reinforcement in extra-clinical situations may be achieved by incorporating parental or familial aid. Numerous programs advocating the use of these "significant others" are available in the literature (Tufts and Holliday, 1959; Sommers, Furlong, Rhodes, Fichter, Bowser, Copetas, and Saunders, 1964; Enge1 et a1., 1966; Wing and Heimgartner, 1973; Coste1lo and Bosler, 1976; Carrier, 1977). Dickson (1962) and Andersland (1961) suggest that maternal attitudes, behavior and environmental factors influence the success of speech management. Due to this influence Sommers et a1. (1964) advise parental education, training, and contact be maximized for speech management facilitation. Research indicates the use of parents may increase stimulus generalization from clinic or school to the home situation. In this manner, carry-over may be expedited and long-range production retention achieved.

Three primary steps seem to constitute successful parent programs. The first involves parent training by the professional with and without the client present. Instruction includes auditory discrimination and listening training for the target sound and the incor- 
rect production, as well as dissemination of basic behavior modification techniques. The parent is counseled regarding reinforcers, punishment, threatening situations, and the type of expected parentchild interaction. Step two involves parent implementation of a structured program or activity which is consistent with management by the speech-language pathologist. The program should include specified lesson plans and objectives, parent antecedent and consequent events, expected child responses, and branching suggestions. Step three requires intermittent parent-clinician contact for questions, goal modification, parent input regarding degree of success, and program evaluation.

Tufts and Holliday (1959) found no significant difference between trained parents and professionals working on articulation during the management phase with pre-schoolers. Further research indicates the use of trained family members is effective and advantageous to the burdened clinician (Fudala, England, and Ganoung, 1972; Wing and Heimgartner, 1973; Costel1o and Bosler, 1976; Carrier, 1977). However, the use of parents may not currently be a reasonable expectation. In the majority of American households, both parents work at least parttime and neither may be willing to devote the time necessary to institute and maintain a program.

The extra-clinical incorporation of teachers has also been proposed to facilitate carry-over. Engel et al. (1966) suggest facilitation could be accomplished through overt reactions to improved productions, or establishing "better speech clubs" in which a competitive element for carry-over achievement is induced. Classroom teachers 
also might encourage and monitor articulation production of a client during group and individual oral reading tasks, during client oral presentations, or when the client is questioned during class activities. The cooperative teacher might even reserve individual time with the client for production of key words and sentences.

Utilization of teacher participation requires the clinician initially meet with the classroom instructor for listening and behavior training. Following program institution the clinician and teacher need to maintain periodic contact to monitor the client's speech behavior and progress, in order to alleviate any difficulties that arise. Due to the additional teacher time and effort necessary the clinician may find problems in program initiation (clauson and Kopatic, 1975). It may be expectations of teacher participation make unfair demands and should not be assumed unless teacher enthusiasm warrants. Polson's (1980) study indicated that although teachers are engaged for carry-over purposes by 94 percent of the clinicians, they are ranked as third in perceived effectiveness. Phelps and Koenigsknecht (1977) report that classroom teachers of Grades 1-3 hold moderately favorable attitudes toward school speech and language programs and to the statement that elementary school children generalize progress made in clinic to outside situations. Teachers of Grades 4-6 hold less than favorable attitudes to the latter statement. Perhaps this discrepancy between attitudes and effectiveness can be partially explained by the Clauson and Kopatic (1975) study. These authors revealed that although teachers seem to be aware of their strengths and weaknesses in understanding speech disorders, it is questionable that they would be 
willing to improve their knowledge or practice. The speech clinician's presence apparently signals a termination of responsibility or tasks oriented to speech by the teacher.

The reinforcing value of an extra-clinical person has been proposed to have a significant effect on successful carry-over facilitation. Parents, peers, and teachers are obvious choices as they maintain prolonged contact periods with the client. However, due to time and scheduling difficulties these individuals may not be available on a consistent basis to promote articulation carry-over. Engel et al. (1966) and Galloway and Blue (1975) remind clinicians not to forget the possibility of other significant persons in the environment. Coaches, clergymen, janitors, secretaries, and paraprofessional personnel all qualify as social reinforcement and may aid in extending stimulus generalization.

Another alternative for carry-over achievement is self-evaluation by the client. McReynolds (1972) found that transfer increases when the client is required to monitor the accuracy of his own articulation. Diedrich (1971) felt that self-monitoring is a necessary component of speaking. Engel and Groth (1976) investigated these observations by incorporating self-evaluation signaling procedures. All subjects attained correct target phoneme production and maintained this behavior throughout the academic year. Polson's (1980) study found that 83 percent of the clinicians surveyed use self-evaluation procedures and 70 percent rank this method among the three most effective.

Review of the literature indicates that a variety of carry-over 
techniques is available. Most are documented in some manner and all have gained support at some time. 
CHAPTER III

METHODS AND PROCEDURES

Methods

\section{Subjects}

Participants in this investigation included 4 children, 3 boys and 1 girl, ages 8-3 to 11-0, currently attending public elementary school. Al1 subjects were determined to be within the normal receptive vocabulary range of 85 to 115 as demonstrated by a Peabody Picture Vocabulary Test Form B (Dunn, 1965), administered by the investigator (see Appendix A). All subjects had been identified as articulation disordered, displaying a lingually distorted /s/. All subjects were stimulable for /s/ in isolation. The children and their parents were contacted for interviews and an explanation of program management prior to program initiation. Both parent and child signed informed consent permission forms. The subjects were divided randomly into 2 groups of 2 each for purposes of the study. Group A was comprised of 2 boys ages 8-11 and 11-0. Group B was comprised of 1 boy and 1 girl ages 8-2 and 8-3 respectively. An audiometric screening evaluation was administered by this investigator. All subjects demonstrated hearing acuity within normal limits in at least one ear. The frequencies of $500 \mathrm{~Hz}, 1000 \mathrm{~Hz}$, $2000 \mathrm{~Hz}, 4000 \mathrm{~Hz}$, and $6000 \mathrm{~Hz}$ were tested at $20 \mathrm{~dB}$. 


\section{Diagnostic Instrumentation}

Each subject received a diagnostic evaluation including two standardized measures and a conversational speech sample. The Hjena Deve1opmental Articulation Test was administered as a global examination (see Appendix B).

The McDonald Deep Test of Articulation by McDonald (1964) was used to identify any differences of target sound production in articulation environments (see Appendix $\mathrm{C}$ ). The Deep Test evaluates sound production in releasing and arresting positions using a combination of pictures to elicit responses.

A conversational speech sample was obtained from each child to evaluate /s/ production during the dynamic process. All responses were recorded on a reel-to-reel Pioneer RT 1020L tape recorder.

Hearing screening was accomplished using a Beltone $15 \mathrm{C}$ portable audiometer.

\section{Program Instrumentation}

The /s/ /z/ Articulation Modification Program (Collins and Cunningham, 1977) was chosen as the programmed management procedure. The 52-step/S/AMP utilizes imitative and picture-elicited responses to evoke and maintain correct $/ \mathrm{s} / / \mathrm{z} /$ production. Due to the nature of this study steps requiring home carry-over activities were omitted. A token reinforcement system provided reward of correct responses. 


\section{Procedures}

\section{Test Administration}

All tests were administered by the investigator according to manual instructions. Both the Hjena Test and the Deep Test used pictures for sound elicitation. The conversational sample was obtained through open-ended questions asked by the investigator. For a sample of these questions see Appendix D.

\section{Program Administration}

Four subjects were divided into 2 groups of 2 . Each group received identical instruction during 25-minute sessions 3 times weekly by the investigator according to /S/AMP outline. When participants in each group produced $/ \mathrm{s} /$ and $/ z /$ in conversation in the clinic setting, 2 carry-over techniques were implemented, 1 per group. The students were given grid cards (see Appendix E) on which /s/ and /z/ productions were to be recorded. Each child received an opportunity to practice using the grid card in a role-played situation.

Group A carry-over activities involved evaluations of articulation by significant others in the subject's environment, such as secretaries, janitors, teachers, and aides. The child approached a 1 istener of his choice, asking that person to evaluate his /s/ /z/ productions in sentences. During the child's utterance the listener marked an $\mathrm{X}$ on the grid card for correct production and an 0 for incorrect productions. Prior to any child contact these significant others were informed of the study and briefed as to appropriate reactions.

Group B carry-over activities involved a self-monitoring process. 
The child was required to monitor his own $/ \mathrm{s} /$ and $/ z /$ productions during a conversation, marking the appropriate $\mathrm{X}$ or 0 on the grid card as the sounds were produced. The time of day and/or conversation chosen was strictly up to the child.

The investigator requested students and parents not to utilize the parents during recorded carry-over activities as this method has been previously studied with positive results. None of the groups was directed to use the grid card a specific number of times per day. The only prescription was that the children use it daily. A modified reinforcement system was maintained throughout carry-over. The students received stickers when grid cards were brought to speech class. Each child's daily progress was charted. The children maintained contact with the investigator three times weekly throughout carry-over. The groups were seen separately for ten minutes each to tabulate and chart progress. No management instruction was given at this time. Carryover procedures continued for three weeks, after which time a posttest evaluation was administered and the subjects were observed covertly by the investigator during lunch and play activities to determine if carry-over had actually been achieved in untrained conversational situations.

\section{Post-test Evaluation}

Subjects were post-tested three weeks after carry-over procedures had been implemented. Each was administered the pre-test battery. The investigator measured carry-over attainment through parent interview, teacher interview, and by covert observation of the child during lunch and play activities on two consecutive days. The 
investigator counted the frequency of correct and incorrect /s/ and $/ z /$ productions during these observations.

Data Analysis

Scoring of all standardized tests was done according to test manual instructions. Descriptive statistics were used to compare the effectiveness and efficiency of both carry-over techniques. 
CHAPTER IV

RESULTS AND DISCUSSION

\section{$\underline{\text { Results }}$}

This investigation sought to answer the following questions:

Did both techniques achieve carry-over?

Did one technique facilitate conversational carry-over achievement within a shorter time period?

Was one technique more cost efficient in terms of clinician-child contact time, number of correct responses, and/or reinforcement schedules maintained?

Both techniques achieved carry-over to a certain degree, with Group A showing the greatest gain in all measures. Group A (selfmonitors) displayed 78 and 80 percent correct production of the phoneme in conversation during the covert post-test while Group B (significant others) only attained 5 and 38 percent (see Table I).

\section{TABLE I}

AVERAGE PERCENTAGE OF CORRECT CONVERSATIONAL PRODUCTIONS DURING TWO COVERT OBSERVATIONS

\begin{tabular}{ccc}
\hline \hline Group & Subject & Average \% \\
\hline \multirow{2}{*}{ A } & 1 & 78 \\
& 2 & 80 \\
B & 3 & 5 \\
& 4 & 38 \\
\hline
\end{tabular}


Additionally, Group A achieved higher overall percentage gains in single words (see Table II), as well as conversation during the posttest (see Table III) and covert observation samples (see Table I).

TABLE II

MCDONALD DEEP TEST SINGLE WORDS

Pre- AND POST-TEST RESULTS

\begin{tabular}{ccccc}
\hline & & & & \\
Group & Subject & $\%$ Pre- & $\%$ Post & $\begin{array}{r}\text { Overa } 11 \\
\% \text { Gain }\end{array}$ \\
\hline \multirow{2}{*}{ A } & 1 & 5 & 97 & 92 \\
& 2 & 17 & 87 & 70 \\
B & 3 & 10 & 37 & 27 \\
& 4 & 2 & 87 & 85 \\
\hline
\end{tabular}

TABLE III

CONVERSATIONAL SAMPLE PRE- AND POST-TEST

RESULTS PERCENTAGE CORRECT

\begin{tabular}{ccccc}
\hline \hline Group & Subject & $\%$ Pre- & \% Post- & $\begin{array}{r}\text { Overall } \\
\% \text { Gain }\end{array}$ \\
\hline \multirow{2}{*}{ A } & 1 & 0 & 82 & 82 \\
& 2 & 11 & 90 & 79 \\
\multirow{2}{*}{ B } & 3 & 1 & 11 & 10 \\
& 4 & 0 & 43 & 43 \\
\hline
\end{tabular}

Subjects utilizing the self-monitoring procedure (Group A) reported higher numbers of correct responses on their grid cards in a shorter period of time than those using the significant others tech- 
nique (Group B), as shown in Figure 1. At the one-week juncture during the carry-over procedures the self-monitors (Group A) reported 83 percent more correct responses than those using significant others (Group B). At the two-week juncture Group A reported 86 percent more correct responses than Group B. At the three-week juncture Group A reported 76 percent more correct responses than Group B.

In terms of cost efficiency, both techniques utilized the same clinician-child contact time and reinforcement schedules. However, Group A (self-monitors) reported higher numbers of correct responses on their grid cards than Group B (significant others), as shown in Figure 1 .

According to these percentage figures, the self-monitors (Group A) demonstrated greater gain of correct productions in word and conversational contexts. This gain appeared to be consistent in all situations studied. All subjects, regardless of technique used, showed a higher percentage gain for single word contexts than conversational contexts (see Tables II and III). The number of correct productions during carry-over, as recorded on each subject's grid card, may have proportionally affected the overall gain measured in conversation. The self-monitors reported higher correct productions over the three-week carry-over period than the group using significant others (see Figure 1). Regardless of the number of correct productions all subjects seemed to follow a three-part trend during carryover activity (see Figure 1). Initially, the subjects' number of correct productions increased dramatically. This was followed by a decrease in correct productions. The third stage seemed to be a 


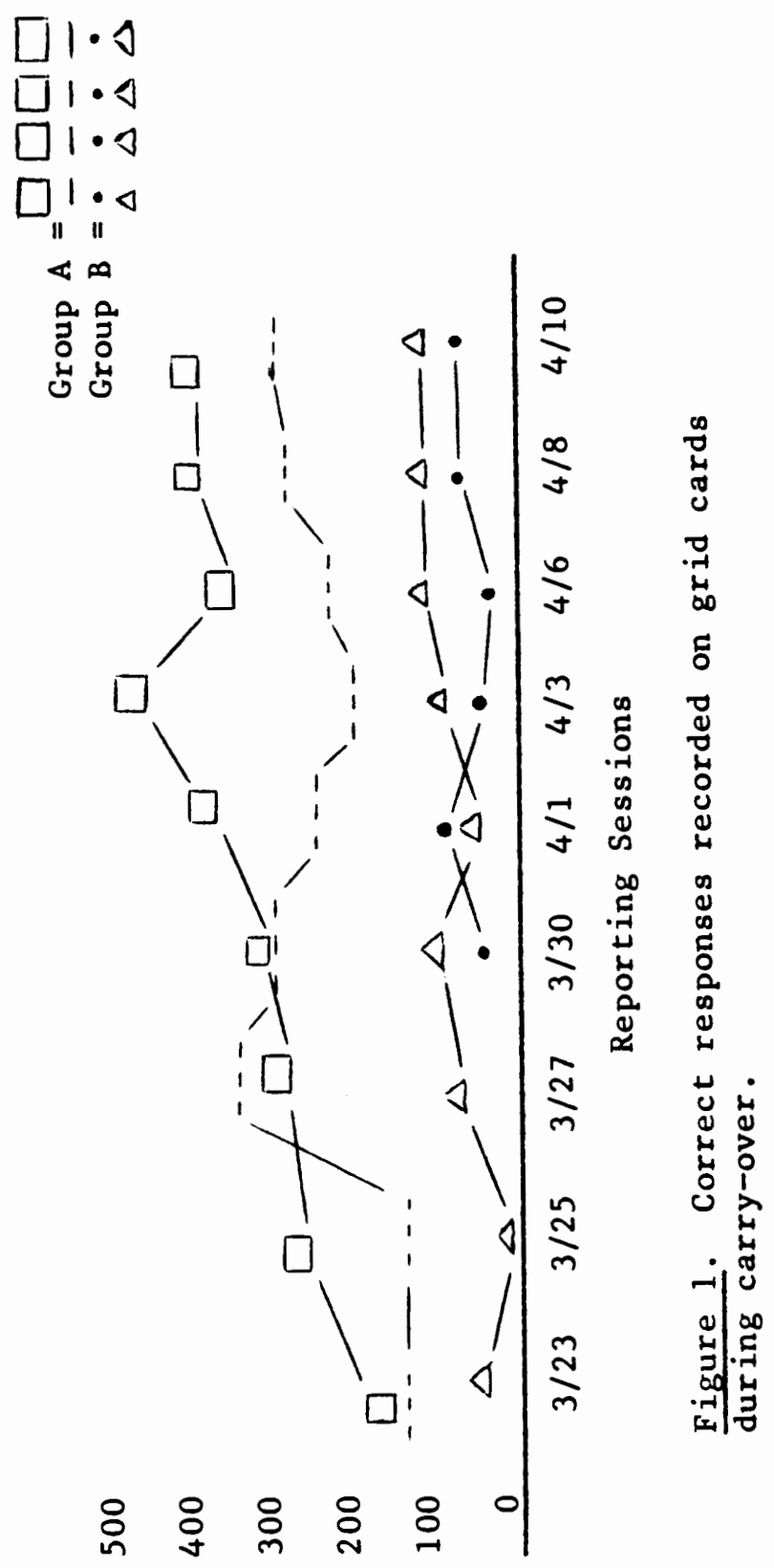

səsuodsəy fo səqumN 
leveling off period.

The number of correct sound productions in carry-over activities appeared to be proportionally affected by the number of days in attendance (see Table IV) in management.

TABLE IV

CORRECT PRODUCTIONS REPORTED IN CARRY-OVER

COMPARED TO ATTENDANCE

\begin{tabular}{cccc}
\hline & \multicolumn{3}{c}{ Total Correct Productions } \\
Group & Subject & Reported in Carry-over & Attendance \\
\hline \multirow{2}{*}{ A } & 1 & 3240 & 19 \\
& 2 & 1925 & 18 \\
B & 3 & 320 & 13 \\
& 4 & 620 & 17 \\
\hline
\end{tabular}

\section{Discussion}

Due to the fact that human behavior is not consistent among individuals, any interaction that seeks change in that behavior must be cautiously interpreted. In this two-phase investigation a variety of possible behavioral influences became evident during the management and/or carry-over process. The degree to which these factors influenced results of this study is unknown.

Management Influences on Carry-over

The skills required to perform carry-over activities were learned in the management phase. Carry-over performance appeared to be influenced by several factors found in management. These factors included 
motivation, the ability to read, attendance, weekly scheduling, management procedures, and criteria for movement within the management program.

Motivation determines performance (Tarpy, 1975). The degree of incentive or the cause for action in this management situation initially appeared linked to social or tangible reinforcement. Over the management period, all students modified this incentive to include intrinsic motivation or an expansion of the $\mathrm{S}^{\mathrm{D}} \mathrm{s}$.

Reading ability influenced this investigation as the better readers gave more correct responses and performed those responses faster under time pressure than the poor readers.

Level of attendance in the management setting seemed to have a proportionate effect on performance; less attendance produced fewer correct responses.

Students modify articulation more rapidly when management is available daily, rather than on a less frequent schedule. Since children in this study were seen three times weekly, the results may not be comparable with clinicians providing management more or less of ten.

In an investigation of this nature it was necessary to separate management and carry-over procedures. Generally, tasks in these categories are meshed to facilitate the modification process. Requiring no carry-over activities in the management phase is unreasonable and likely affected movement and success in both management and carry-over sessions. Additionally, requiring no direct management activities in the carry-over process was also artificial. If these procedures were used in a non-study environment, the purpose of terminal carry-over 
would be defeated.

Although the sequence of steps for management is generally consistent throughout articulation programs, the criterion for movement between those steps is not. The possibility exists that a higher criterion may affect the outcome of management and/or carry-over. Consistent automatic production of a phoneme may be achieved at varying times for each individual at any point in the modification process. If criterion for movement between steps is increased, automatization and habituation may endure more readily than if the criterion is less.

Obviously, the factors possibly influencing the outcome of the management process were many. Differences in these factors lie in the type and degree of effect generated in each session. Their similarity is only that each is caused by the unpredictable nature of human subjects.

\section{Influences on Carry-over}

Motivation

As with the management process, motivation was a significant influence during carry-over. Participants in the "self-monitoring" group appeared to function with intrinsic incentives as they judged productions themselves without immediate social reinforcement from another person. Participants in the significant others group appeared to function with social reinforcement and external motivation provided by immediate acknowledgement from another person. This apparent difference in the type of motivation may have influenced the outcome of carry-over in the grid card phase and during covert observation. The 
self-monitors were not dependent on others and could use the grid card at their leisure during the day. If the self-monitors found the grid card and self-responsibility process rewarding, they would be more likely to monitor themselves when no grid card was present. The results indicated the self-monitors practiced more frequently during carry-over, producing more correct responses with the grid card and during covert observation than the other participants. Conversely, if the subjects using significant others felt little or no reward from the reactions of others and had not developed intrinsic incentives, they would likely use the grid card less and produce fewer correct responses during covert observation. The results of this study indicated those using significant others did in fact react in this fashion.

Age and Maturity

The carry-over techniques and the reporting vehicle (grid card) chosen for this study may have influenced the entire process because each required a certain degree of social and academic maturity to complete. All subjects were to bring grid cards to every session and were required to use the cards daily. This meant remembering speech days and activities without being prompted. The students using significant others had to converse specifically with adults. The subjects needed an understanding of the grid card process and the purpose of speech class. They had to be familiar with turn-taking and basic social manners for a group situation. If a child lacked the necessary maturity, this could slant progress and results. The children in this study were between the ages $8-2$ and 11-0. Group A was comprised of 
the older children, while Group B included the younger students.

Attendance

It is rare that a clinician has no contact with a student during the carry-over phase. Attendance at carry-over sessions was felt to be significant because contact with the clinician as an $S^{D}$ provided reinforcement of a newly learned skill. Without that reinforcement or reminder the student was likely to lose the skill, replacing it with the old articulation habit. One child missed 33 percent of carry-over sessions and post-test evaluations produced the fewest correct responses in any context.

Management Procedures

The restriction of no carry-over activities in the management phase could have influenced the results of carry-over as there was no small sequential progression from management to carry-over activities. The sudden absence of consistent practice with the clinician and the sudden introduction of novel tasks were unrealistic and generally do not occur. Given ideal circumstances, carry-over should be an ongoing process throughout management. If it is not, carry-over activities may be less successful and take longer to achieve.

\section{Criterion for Carry-over}

The criterion for movement within management corresponds closely with the criterion for movement within carry-over. The carry-over techniques used in this investigation were implemented for three weeks. This was approximately one-half the time necessary for management procedures to be accomplished. The study's results may have been 
different had carry-over procedures been prolonged for the same amount that time management required or even longer. This lengthening of carry-over practice could affect the habituation process as more practice time is allowed.

Uncontrolled Variables

Certain variables which may have affected the carry-over outcome were not controlled in this study. The first is honesty in reporting on the grid cards. The investigator had no opportunity to observe use of grid cards past the initial practice session and there was no way to check the validity of a child's responses. If a subject wished to create unearned Xs, he could. Additionally, parents were asked to refrain from helping the student with speech, especially carry-over activities. In this study there was no control for any overt or covert parental actions that may have affected the validity and reliability of a child's responses. One provision for this variable might be to require carry-over practice only at school during school hours. The grid card could then be returned daily to the clinician, and given back to the child the following day.

\section{Effect of Factors on Results}

As reported in Chapter IV, participants in the study using selfmonitoring techniques exhibited greater improvement in $/ \mathrm{s} / / \mathrm{z} /$ production in all carry-over contexts tested. However, the results may have been skewed by several factors discussed previously. Although randomly chosen, the self-monitors were older and in a higher grade level than the others. They were better readers and better able to function 
with less adult direction. Perhaps due to a greater maturity level the self-monitors appeared motivated by intrinsic rather than external factors. Combined, these influences may have been a powerful force altering the results positively in all areas tested in favor of the self-monitors. 
CHAPTER V

SUMMARY AND IMPLICATIONS

Summary

The purpose of this investigation was to determine the comparative effectiveness of two articulation carry-over techniques. It was hoped that through this comparison answers regarding carry-over results could be ascertained for purposes of aiding public school clinicians currently spending the majority of management time on carry-over. If one technique was found to be superior, its use among speech pathologists might aid in changing this time allocation trend.

Identical management programs using the Collins and Cunningham (1977) /S/AMP three times weekly were employed by two random groups involving two participants each. All subjects displayed a lingually distorted $/ \mathrm{s} /$ and $/ z /$. Upon achievement of $/ \mathrm{s} / / \mathrm{z} /$ production in conversation in the clinic setting two subjects were assigned carry-over tasks using a self-monitoring procedure. The remaining two subjects were assigned carry-over tasks using significant others. All subjects utilized grid cards as the recording device and both groups continued to meet with the investigator throughout carry-over for charting purposes on $1 y$.

The results indicated the self-monitoring technique to be more effective. The self-monitors demonstrated greater gain of correct production in all contexts studied. However, these results must be 
viewed guardedly due to possible skewing factors of age, maturity, attendance, reading ability, movement criteria, motivation, and honesty of reporting.

\section{Implications}

\section{Research}

Based on the possible factors influencing this investigation, future research dealing with articulation carry-over comparisons should address these problems. One procedure, although time consuming, involves following the same investigative paradigms used here but increasing the number of subjects used. A greater number of participants increases the opportunity for better reliability and validity of statistics. If enough subjects were involved, a statistical analysis could be utilized.

Addressing the problem of a lack of honesty in reporting, future studies might choose to use the same paradigm but replace the recording device used for carry-over responses. The students might taperecord speech samples in other environments outside the clinic setting and give them to the clinician. Another possibility may involve more tracking by the listener, rather than the speaker.

Another investigation procedure using the same paradigms but substituting older participants, perhaps in the age range of 9-0 to 12-0, might yield new results. As previously discussed, age and maturity level influence both management and carry-over activities. Age controls should mediate inconsistencies in progress sometimes common to younger children. Older subjects might progress faster and require 
different reinforcement or motivational activities.

Age controls might also be the framework for an investigation comparing one carry-over technique with two or more different age groups. If self-monitoring is used as the chosen technique, age ranges of $7-0$ to $8-0,9-0$ to $10-0$, and $11-0$ to $12-0$ are suggested. The results from a study of this nature may indicate that a specific carry-over technique is most effective with a specific age of children. Using children below age seven for a comparison study of $/ s / / z /$ is not recommended as positive results could be attributed to maturation. Such an age-specific investigation would be beneficial to the school clinician pressed for time as it would increase the probability of success with particular groups of children.

According to Polson's (1980) study, Oregon school clinicians ranked self-evaluation techniques and having the client work with individuals other than the clinician within the top three perceived most effective. Perhaps another investigation could compare the effectiveness of other carry-over techniques. One possibility would be to compare using self-monitors with the assignment of various homework tasks. Another possibility would be to compare the use of significant others in the client's environment with the use of reminders distributed in the client's environment. With a series of studies of this nature a hierarchy of techniques could be developed for use by school clinicians.

$\underline{\text { C1inica1 }}$

The evidence supports the conclusion that the self-monitoring technique, as used in this investigation, was superior in overall 
achievement of carry-over compared to the significant others technique for children eight to eleven years of age. However, any carry-over technique holds possible merit for particular children due to the fact that different individuals are motivated by different tasks. In the final analysis it seems obvious that the conscientious clinician will continue to design activity programs based on individual needs. The carry-over technique chosen to supplement each program should be appropriate to the child's age and personality. Although the clinic room may become a testing ground of sorts under these circumstances, the flexible clinician will be able to serve the needs of the students more effectively and efficiently. 


\section{B IBLIOGRAPHY}

ANDERSLAND, P. B., Maternal and environmental factors related to success in speech improvement training. J. Speech Hrng. Res. $4(1), 79-90$ (1961).

BANKSON, N. W., and BYRNE, M. C., The effect of a timed correct sound production task on carry-over. J. Speech Hrng. Res. 15, 160-168 (1972).

BLACK, M., and LUDWIG, R. A., Analysis of the games technique. J. Speech Hrng. Dis. 21, 183-187 (1956).

CARRIER, J. K., A program of articulation therapy administered by mothers. J. Speech Hrng. Dis. 35(4), 344-353 (1977).

CHAPMAN, M. E., HERBERT, E. L., AVERY, C. B., and SELMAR, J. W., C1inical practice: Remedial procedures. J. Speech Hrng. Dis. Monog. Supp. 8, 58-77 (1961).

CHISUM, L., Relationship between remedial speech instruction activities and articulation change. Master's thesis, Univ. of Kansas. In Communication Disorders: Remedial Principles and Practices. Glenview, I11.: Scott, Foresman and Co. (1974).

CHISUM, L., SHELTON, R. L., ARNDT, W. B., and ELBERT, M., Relationship between remedial speech instruction activities and articulation change. Cleft Palate J. 6, 57-64 (1969).

CLAUSON, G. M., and KOPATIC, N. J., Teacher attitudes and knowledge of remedial speech programs. Lang. Speech Hrng. Serv. Schools 6 , 206-211 (1975).

COLLINS, P. J., and CUNNINGHAM, G. W., Articulation Modification Program. Beaverton, Ore.: C. C. Publication, Inc. (1977).

COSTELLO, J., and BOSLER, S., Generalization and articulation instruction. J. Speech Hrng. Dis. 41, 359-375 (1976).

DICKSON, S., Differences between children who spontaneously outgrow and children who retain functional articulation errors. J. Speech Hrng. Res. 5(3), 263-271 (1962).

DIEDRICH, W. M., Procedures for counting and charting a target phoneme. Lang. Speech Hrng. Serv. Schools 5, 18-32 (1971). 
DUNN, L. M., Peabody Picture Vocabulary Test. Circle Pines, Minn.: American Guidance Service (1965).

ENGEL, D. C., Promoting social reinforcement for articulation carryover. N. Dak. Speech Hrng. 12, 29-33 (1968).

ENGEL, D. C., BRANDRIET, S. E., ERICKSON, K. M., GRONHOVD, K. D., and GUNDERSON, G. D., Carry-over. J. Speech Hrng. Dis. 31, 227-233 (1966).

ENGEL, D. C., and GROTH, L. R., Case studies of the effect on carryover of reinforcing postarticulation responses based on feedback. Lang. Speech Hrng. Serv. Schools 7(2), 93-101 (1976).

ENGEL, D. C., and MAHONEY, W. D., Measurement of the effect of a carry-over technique. Ohio J. Speech and Hrng. 6(2), 97-104 (1971).

EVANS, C. M., and POTTER, R. E., The effectiveness of the S-Pack when administered by sixth-grade children to primary grade children. Lang. Speech Hrng. Serv. Schools 5(2), 85-90 (1974).

FUDALA, J. B., ENGLAND, G., and GANOUNG, L., Utilization of parents in a speech correction program. Except. Child. 38, 407-412 (1972).

GALLOWAY, H. F., and BLUE, M. C., Paraprofessional personnel in articulation therapy. Lang. Speech Hrng. Serv. Schools 6(3), 125-130 (1975).

GERBER, A., Goal Carry-over: An Approach to Articulation Therapy. Philadelphia: Temple University Press (1970).

GRAY, B. B., A field study on programmed articulation therapy. Lang. Speech Hrng. Serv. Schools 5(3), 119-125 (1974).

HARRYMAN, E., and KRESHECK, J. D., A structured program for modifying $/ \mathrm{r} /$ misarticulations. Lang. Speech Hrng. Serv. Schools 5, 52-54 (1971).

JOHNSON, M. P., A study of carry-over practices of school clinicians in North Dakota. In D. C. Engel and L. R. Groth, Lang. Speech Hrng. Serv. Schools 5(2), 93-101 (1976).

JOHNSTON, J. M., and JOHNSTON, G. T., Modification of consonant speech sound articulation in young children. J. App1. Behav. Ana1. 5, 233-246 (1972).

KALASH, S. L., A study of a carry-over technique for articulation therapy. Master's thesis, Univ. of N. Dak. (1970).

MARQUARDT, E., Carry-over with speech pals. J. Speech Hrng. Dis. 24, 154-157 (1959). 
McDONALD, E. T., A Deep Test of Articulation. Pittsburgh: Pittsburgh Stanwix House (1964).

McINTYRE, B. M., and McWILLIAMS, B. J., Creative dramatics in speech correction. J. Speech Hrng. Dis. 24(3), 275-279 (1959).

McLEAN, J., and RAYMORE, S., Programmatic Research on a Systematic Articulation Therapy Program: Carry-over of Phoneme Responses to Untrained Situations for Normal Learning Public School Children. Parsons, Kan.: Parsons Research Center Report No. 6 (1972).

McREYNOLDS, L., Articulation generalization during articulation training. Lang. Speech Hrng. Serv. Schools 15, 149-155 (1972).

MOWRER, D. E., An analysis of motivational techniques used in speech therapy. ASHA Monog. 491-493 (1970).

MOWRER, D. E., Transfer of training in articulation therapy. J.Speech Hrng. Dis. 36, 427-446 (1971).

MOWRER, D. E., Methods of Modifying Speech Behaviors. Ohio: Charles E. Merrili Publishing Co. (1977).

MOWRER, D. E., BAKER, R. L., and SCHUTZ, R. E., Modification of the Frontal Lisp-Programed Articulation Control Kit. Palos Verdes, Calif.: Educational-Psychological Research Associates (1970).

PHELPS, R. A., and KOENIGSKNECHT, L., Attitudes of classroom teachers, learning disabilities specialists, and school principals toward speech and language programs in public elementary schools. Lang. Speech Hrng. Serv. Schools 8, 33-45 (1977).

POLSON, J., A survey of carry-over practices of Oregon public school clinicians. Master's thesis, Portland State Univ. (1980).

POWERS, M. H., Clinical and educational procedures in functional disorders of articulation. In L. E. Travis (Ed.), Handbook of

Speech Pathology. Englewood Cliffs, N.J.: Prentice Hall (1971).

RACHLIN, H., Introduction to Modern Behaviorism. San Francisco: W. H. Freeman and Company (1976).

RYAN, B. P., A study of the effectiveness of the S-Pack Program in the elimination of frontal lisping behavior in third-grade children. J. Speech Hrng. Dis. 36, 390-396 (1971).

SLOANE, H. N., and MacAULAY, B. D., Operant Procedures in Remedial Speech and Language Training. New York: Houghton Mifflin (1968). 
SOMMERS, R. K., FURLONG, A. K., RHODES, F. E., FICHTER, G. R., BOWSER, D. C., COPETAS, F. G., and SAUNDERS, Z. G., Effects of maternal attitudes upon improvement in articulation when mothers are trained to assist speech correction. J. Speech Hrng. Dis. $42(4), 395-401$ (1964).

SUNDEL, M., and SUNDEL, S. S., Behavior Modification in the Human Services. New York: John Wiley and Sons (1975).

SUTTON, E. L., Integrating speech therapy and language arts. J. Speech Hrng. Dis. 20, 376-379 (1955).

TARPY, R. M., Basic Principles of Learning. Glenview, I11.: Scott Foresman and Co. (1975).

TUFTS, L. C., and HOLLIDAY, A. R., Effectiveness of trained parents as speech therapists. J. Speech Hrng. Dis. 42(4), 395-401 (1959).

VAN RIPER, C., Speech Correction Principles and Methods. Englewood Cliffs, N.J.: Prentice Hall (1972).

WING, D. M., and HEIMGARTNER, L. M., Articulation carry-over procedure implemented by parents. Lang. Speech Hrng. Serv. Schools 4(4), 182-195 (1973).

WINITZ, H., From Syllable to Conversation. Baltimore: University Park Press (1975).

WORTHLEY, W. J., The effect of programmed instruction in the correction of the deviant articulatory production of $/ \mathrm{s} /$. Dissertation, Univ. of Oregon (1970).

WRIGHT, V., SHELTON, P. L., and ARNDT, W. B., A task for evaluation of articulation change: III. Imitative task scores compared with scores for more spontaneous tasks. J. Speech Hrng. Res. 12, 875-884 (1969). 


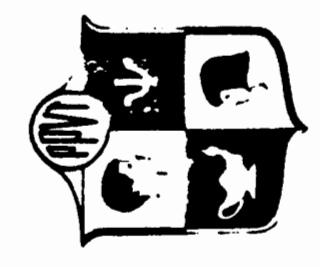

$100=<30 ; 00=<30 ; 000<30 ; 000 \triangle$

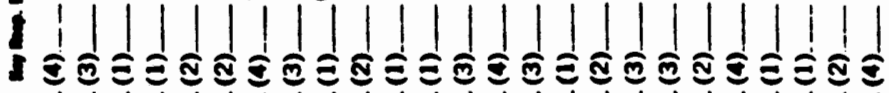

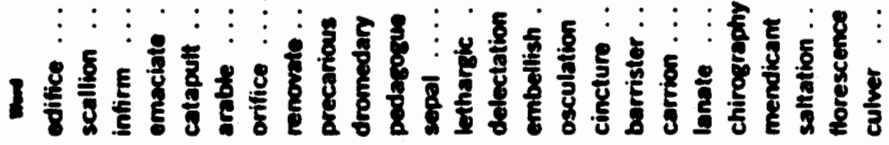
L

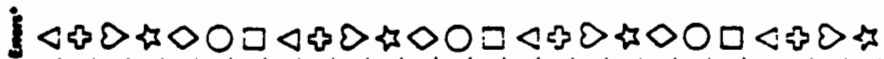

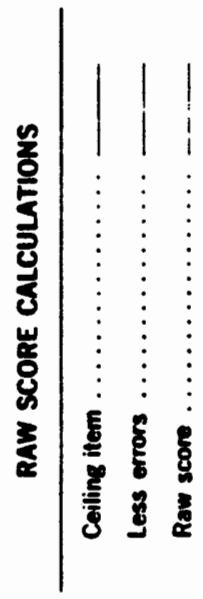

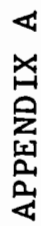

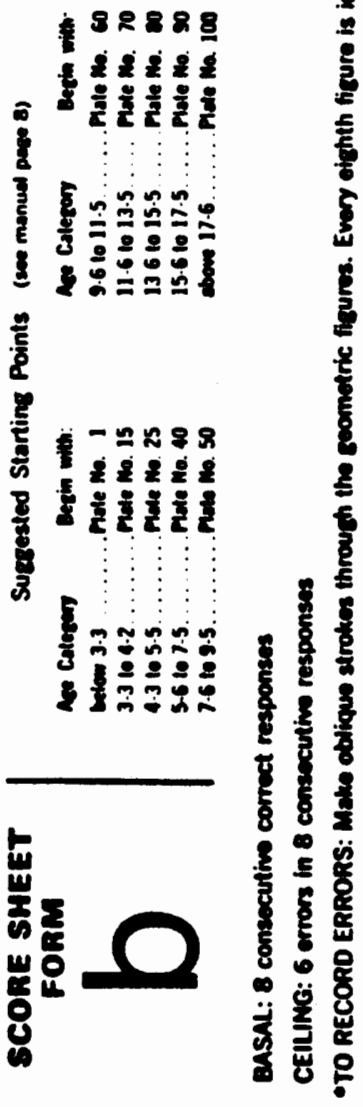

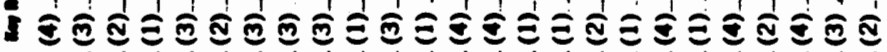

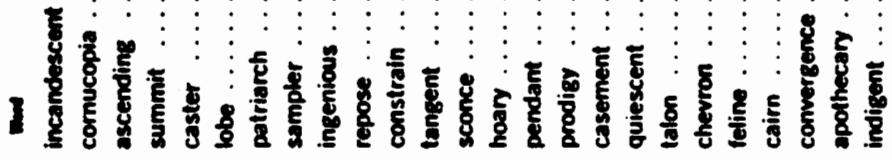
1

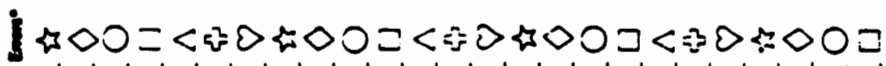
1

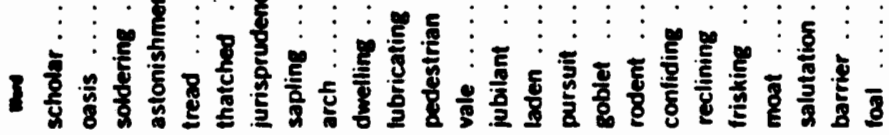

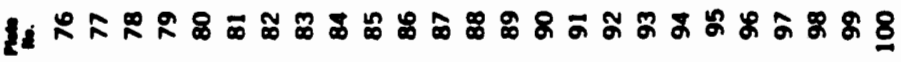

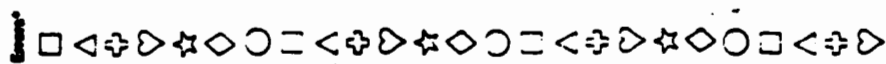

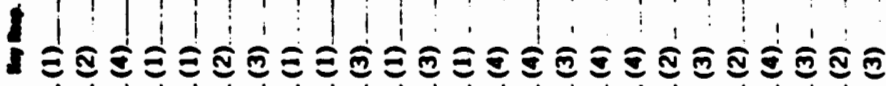

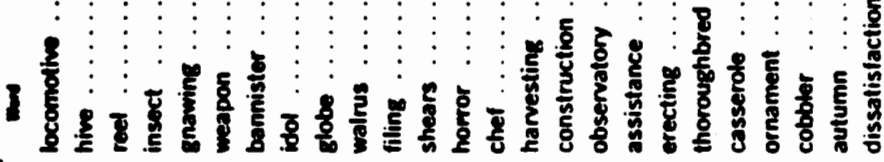

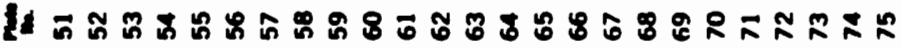

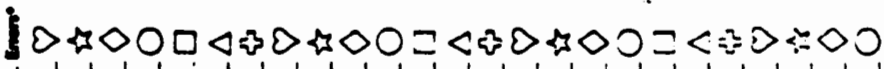

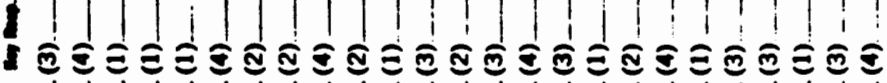

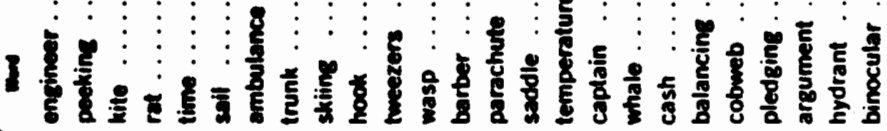

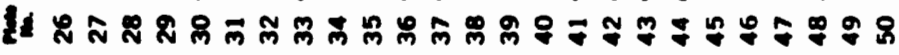

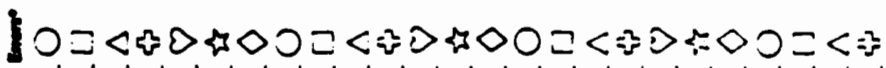

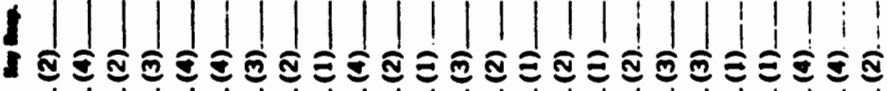

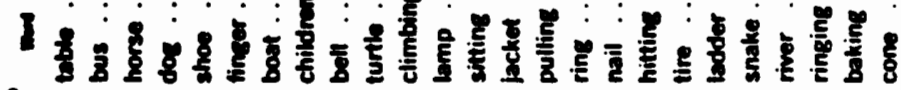
4 4- 


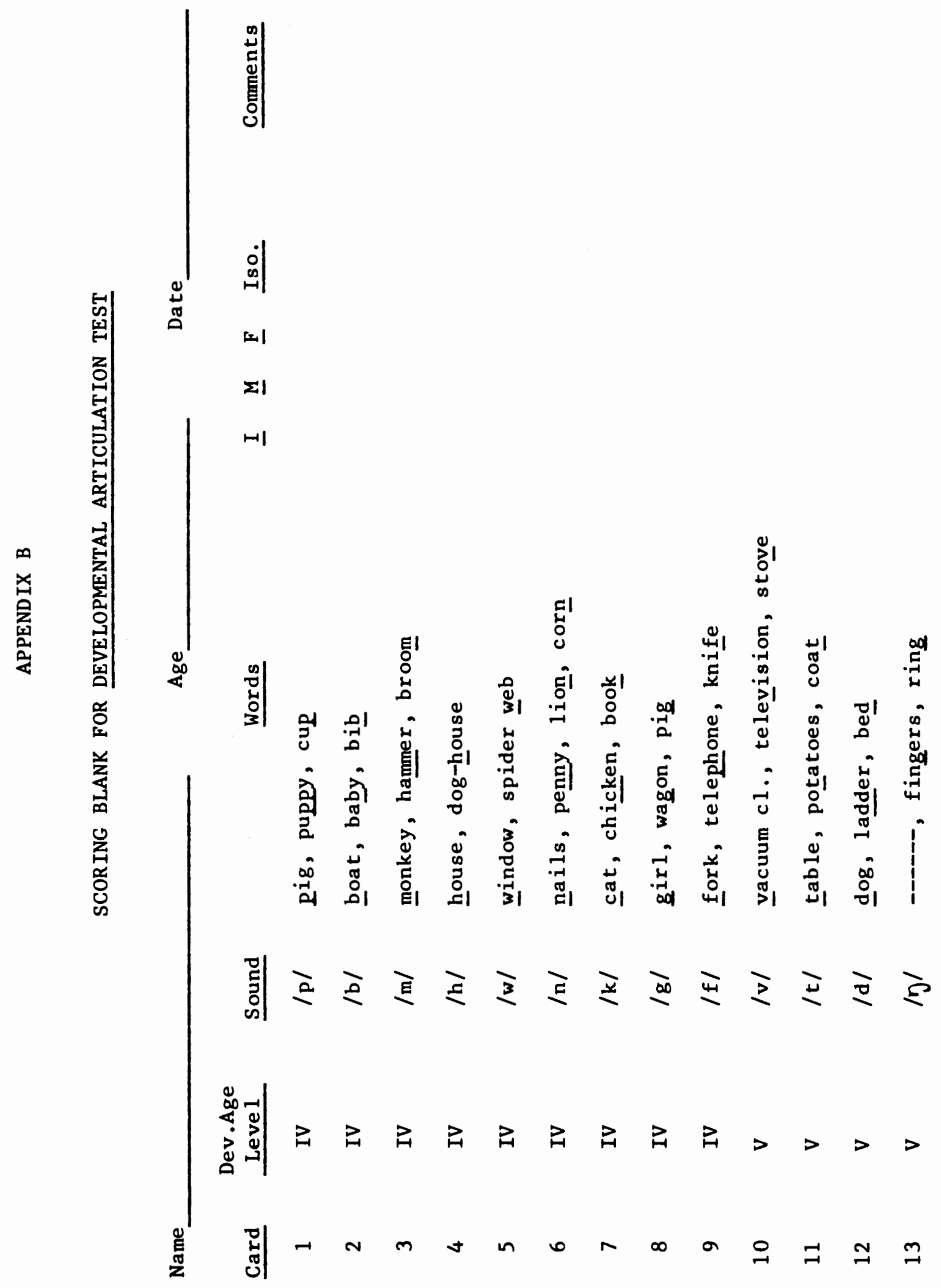


告

龺

in1

$\Sigma I$

$-1$

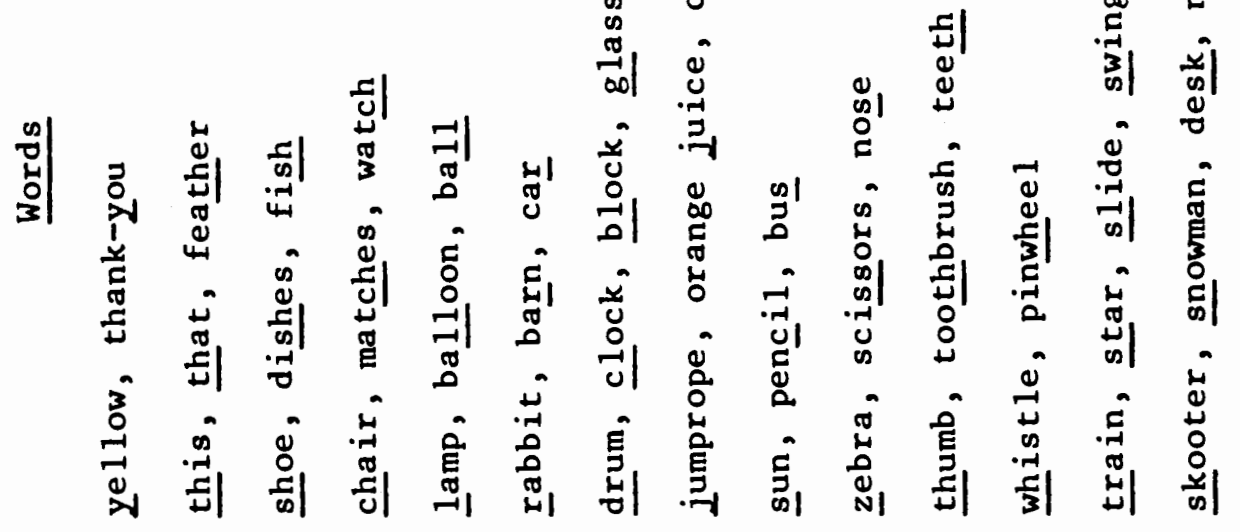

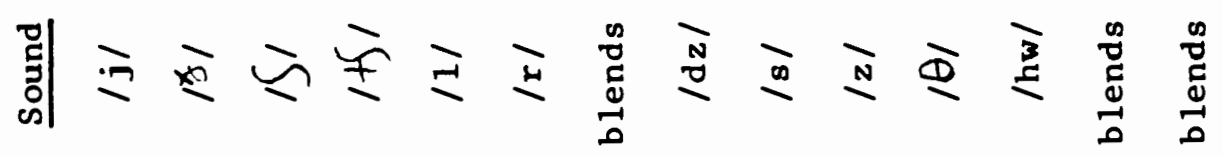

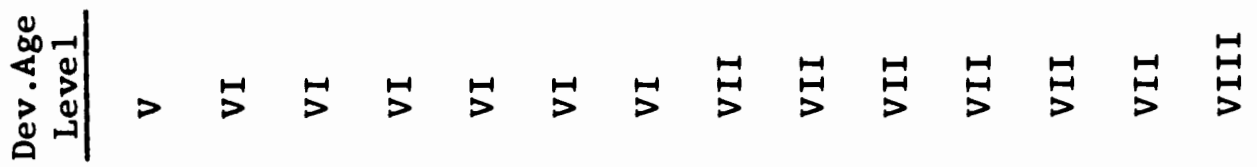

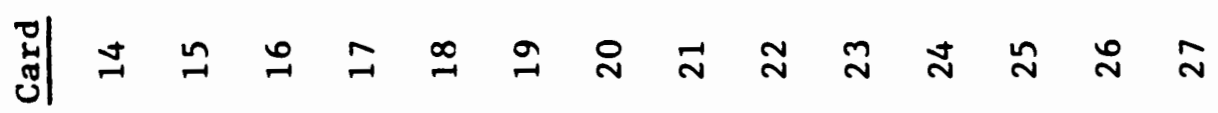




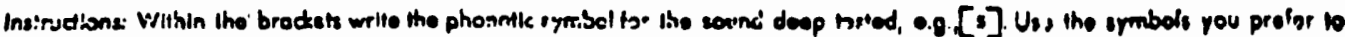

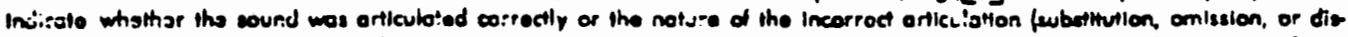

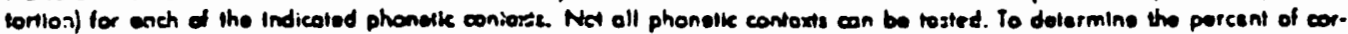

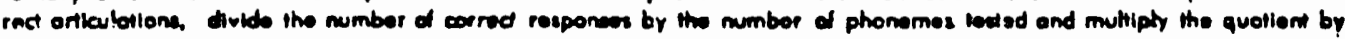
100.

$$
\begin{aligned}
& \text { p - } 1-p \\
& \text { b }-2-b \\
& \text { t }-3-t \\
& \text { d }-4-d \\
& k-5-k \\
& 1-A-0 \\
& m-7-m \\
& n-8-n \\
& \text { 1 }-9-1 \\
& \checkmark-10-7 \\
& 0-11-0 \\
& 5-12-8 \\
& 3-13-5 \\
& 7-14-2 \\
& 5-15-5 \\
& 4 s-16-i j \\
& \text { ds }-.17-\text { is }^{-19} \\
& 1-10-1 \\
& r-17-8 \\
& 1-20-1 \\
& w-21-w \\
& \text { h }-22-h \\
& \text { o }-23-0 \\
& \text { i - } 24-i \\
& 8-25-1 \\
& \text { c }-26-c \\
& =-27-= \\
& \text { A - } 20 \text { - A } \\
& u-29-u \\
& \text { s - } 30 \text { - }
\end{aligned}
$$

\section{SCorroct}

Dole Tested

$$
\begin{aligned}
& p-1-p \\
& \text { b }-2-b \\
& \text { t }-3-t \\
& \text { d }-4-d \\
& k-5-k \\
& 0-6-0 \\
& m-7-m \\
& n-1-n \\
& \text { f }-9-1 \\
& v-10-v \\
& 0-11-0 \\
& 8-12-8 \\
& 3-13-8 \\
& 2-14-2 \\
& s-15-5 \\
& x-10-5 \\
& \text { ds }-17 \div d s \\
& 1-18-1 \\
& r-19-r \\
& 1-20-1 \\
& w-21-w \\
& \text { h }-22-h \\
& 0-23-0 \\
& i-24-1 \\
& \text { I }-25-1 \\
& -20-c \\
& \text { c }-27-0 \\
& \text { A }-28-A \\
& \text { - }-20-4 \\
& \text { ? }-30 \text { 工 }
\end{aligned}
$$

$$
\mathbf{p}-\mathbf{1}-\mathbf{p}
$$$$
\text { b }-2-b
$$$$
1-3-1
$$$$
\text { d }-4-d
$$$$
\text { t }-5-k
$$$$
\text { - }-0-9
$$$$
m-7-m
$$$$
n-8-n
$$$$
\text { f }-9-1
$$$$
v-10-v
$$$$
0-11-0
$$$$
5-12-3
$$$$
\text { - } 13-8
$$$$
2-14-2
$$$$
5-15-5
$$$$
5-16-15
$$$$
d_{3}-17-d_{3}
$$$$
1-18-1
$$$$
8-19-1
$$$$
\mid-20-1
$$$$
w-21-w
$$$$
\text { h }-22-\mathrm{h}
$$$$
\text { o }-23-\mathrm{g}
$$$$
1-24-1
$$$$
\text { I }-25-1
$$$$
\text { e }-20-2
$$$$
\text { e }-27-0
$$$$
\text { A }-28-A
$$$$
\text { a }-29-0
$$$$
\text { ? }-30-3
$$$$
\text { p - } 1-p
$$$$
\text { b - } 2-b
$$$$
\text { t }-3-t
$$$$
\text { d }-4-d
$$$$
\text { t }-5-k
$$$$
\text { - }-6-0
$$$$
m-7-m
$$$$
n-8-n
$$$$
\text { f - }-1
$$$$
v-10-v
$$$$
0-11-0
$$$$
8-12-8
$$$$
\text { s }-13-8
$$$$
2-14-2
$$$$
5-15-5
$$$$
15-16-15
$$$$
\text { ds }-17-d 3
$$$$
1-18-1
$$$$
5-19-?
$$$$
1-20-1
$$$$
w-21-w
$$$$
\text { b }-22-b
$$$$
0-23-0
$$$$
1-24-1
$$$$
1-25-1
$$$$
\text { c }-26-c
$$$$
=-27-2=
$$$$
\text { A }-28-a
$$$$
\text { - }-29-1
$$$$
\text { כ }-30-2
$$

$$
\text { scorred }
$$

\section{SCorred}$$
\text { scorred }
$$

Dolo Ios'od

\section{scorred}

Dolo losted

scorred

Dalo Tested

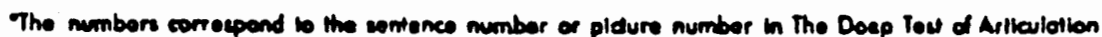




\section{APPENDIX D}

\section{SPEECH SAMPLE SENTENCES}

1. Tel1 me what you did over vacation.

2. Have you ever hurt yourself? Tell me what happened.

3. If I came to your house and looked in your room, what would I find?

4. Pretend you've been chosen for a trip to the moon. What kinds of things would happen to you?

5. Te11 me about your family/pets. 

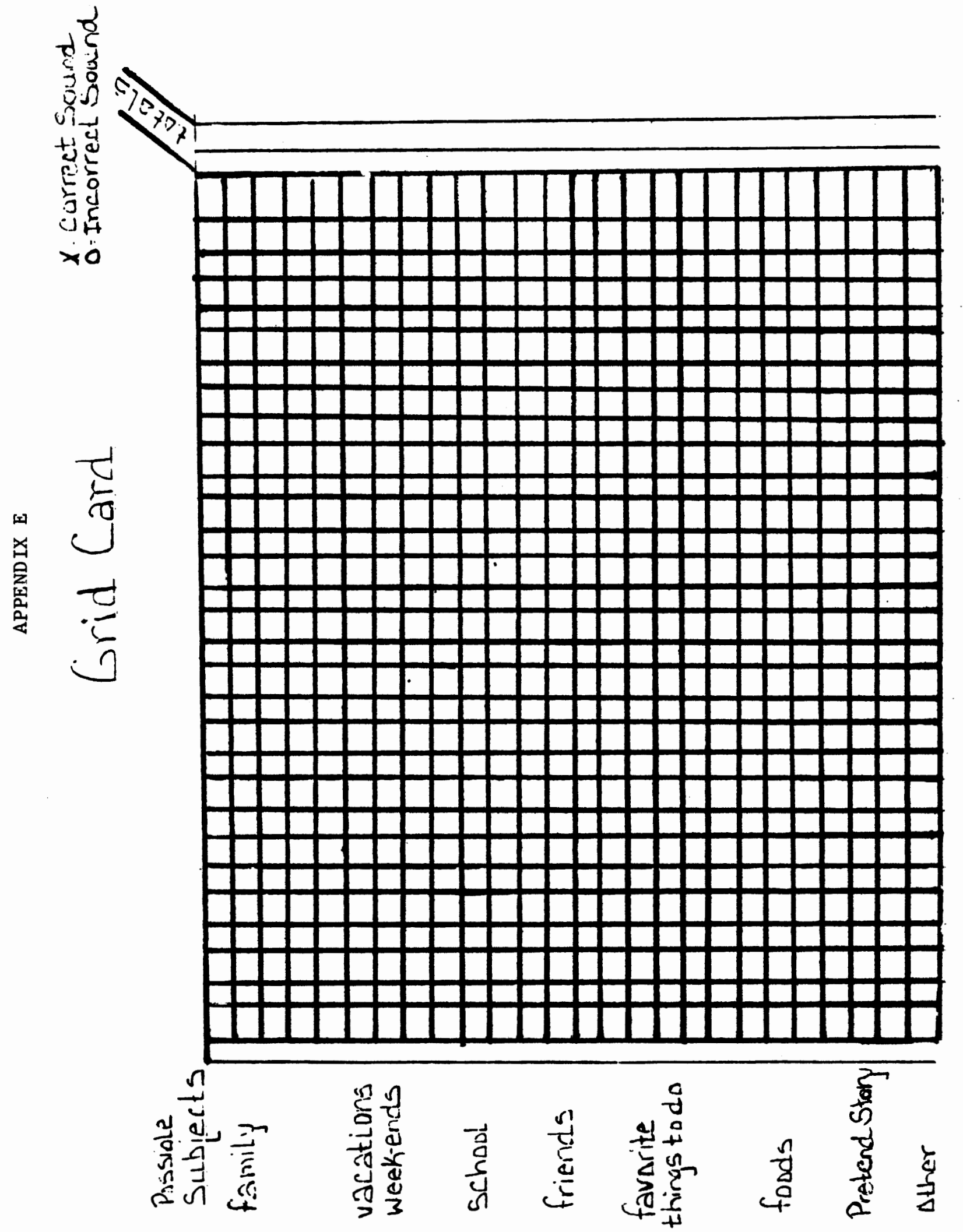